Prepared for the U.S. Department of Energy

under Contract DE-AC05-76RL01830

\title{
Enforcing Building Energy Codes in China: Progress and Comparative Lessons
}
M Evans
MA Halverson
B Shui
A Delgado

August 2010

\section{Pacific Northwest}

NATIONAL LABORATORY

Proudly Operated by Battelle Since 1965 


\title{
DISCLAIMER
}

This report was prepared as an account of work sponsored by an agency of the United States Government. Neither the United States Government nor any agency thereof, nor Battelle Memorial Institute, nor any of their employees, makes any warranty, express or implied, or assumes any legal liability or responsibility for the accuracy, completeness, or usefulness of any information, apparatus, product, or process disclosed, or represents that its use would not infringe privately owned rights. Reference herein to any specific commercial product, process, or service by trade name, trademark, manufacturer, or otherwise does not necessarily constitute or imply its endorsement, recommendation, or favoring by the United States Government or any agency thereof, or Battelle Memorial Institute. The views and opinions of authors expressed herein do not necessarily state or reflect those of the United States Government or any agency thereof.

\author{
PACIFIC NORTHWEST NATIONAL LABORATORY \\ operated by \\ BATTELLE \\ for the \\ UNITED STATES DEPARTMENT OF ENERGY \\ under Contract DE-AC05-76RL01830
}

Printed in the United States of America
Available to DOE and DOE contractors from the Office of Scientific and Technical Information,
P.O. Box 62, Oak Ridge, TN 37831-0062;
ph: (865) 576-8401
fax: $(865)$ 576-5728
email: reports@adonis.osti.gov

\begin{abstract}
Available to the public from the National Technical Information Service, U.S. Department of Commerce, 5285 Port Royal Rd., Springfield, VA 22161 ph: (800) 553-6847 fax: $(703) 605-6900$ email: orders@ntis.fedworld.gov online ordering: http://www.ntis.gov/ordering.htm
\end{abstract}

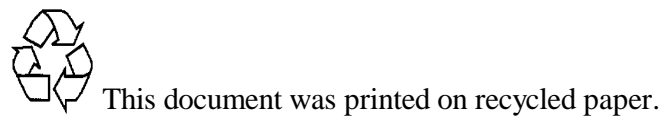




\section{Enforcing Building Energy Codes in China: Progress and Comparative Lessons}

M Evans

B Shui

MA Halverson

A Delgado

August 2010

Prepared for the U.S. Department of Energy under Contract DE-AC05-76RL01830

Pacific Northwest National Laboratory

Richland, Washington 99352 


\title{
Enforcing Building Energy Codes in China: Progress and Comparative Lessons
}

\author{
Meredydd Evans, Bin Shui, Mark Halverson and Alison Delgado \\ Pacific Northwest National Laboratory ${ }^{I}$
}

\begin{abstract}
From 1995 to 2005, building energy use in China increased more rapidly than the world average. China has been adding 0.4 to 1.6 billion square meters of floor space annually ${ }^{2}$, making it the world's largest market for new construction. In fact, by 2020, China is expected to comprise half of all new construction. In response to this, China has begun to make important steps towards achieving building energy efficiency, including the implementation of building energy standards that requires new buildings to be up to $65 \%$ more efficient than buildings from the early 1980s. Making progress on reducing building energy use requires both a comprehensive code and a robust enforcement system.

The latter - the enforcement system - is a particularly critical component for assuring that a building code has an effect. China has dramatically enhanced its enforcement system for building energy codes in the past two years, with more detailed requirements for ensuring enforcement and new penalties for non-compliance. We believe that the U.S. and other developed countries could benefit from learning about the multiple checks and the documentation required in China. Similarly, some of the more user-friendly enforcement approaches developed in the U.S. and elsewhere may be useful for China as it strives to improve enforcement in rural and smaller communities. In this article, we provide context to China's building codes enforcement system by comparing it to the U.S. Among some of the enforcement mechanisms we look at are testing and rating procedures, compliance software, and training and public information.
\end{abstract}

\section{Introduction}

Buildings account for $28 \%$ of Chinese energy consumption (IEA 2009), and this share is likely to grow. The construction pace in China is quite rapid by global standards. From 1995 to 2005 , China had an annual growth rate in building energy use of $1.7 \%$, compared to $1.5 \%$ globally (IEA 2007). The high growth in China's energy use is primarily explained by its commercial sector; China's energy use annual growth rate in commercial buildings was $7.7 \%$, compared to the world average of $2.4 \%$ (IEA 2007). During this same period, China reported adding 0.4 to 1.6 billion square meters of floor space annually (National Bureau of Statistics of China 2008). The World Bank estimates that half of all new global construction through 2020 will be in China. The design and construction of buildings to a large extent sets their energy "footprint" for the duration of their useful life. Because of this and the scale of construction in China, these new buildings will help define global energy and emission trends.

\footnotetext{
${ }^{1}$ The authors would like to acknowledge the U.S. Department of Energy and the U.S. Department of State for their support of this work.

${ }^{2}$ www.stats.gov.cn/english/statisticaldata/yearlydata/.
} 
Building energy codes can play an important role in ensuring that these new buildings will be energy efficient. However, building energy codes are only impactful if they are implemented. China has taken many impressive steps to strengthen implementation of its building energy codes in recent years. This article provides an overview of China's system for implementing its building energy codes. Because China's system is so different from that in the U.S., understanding it first requires knowing who the major actors are, and then how they work together.

China began to adopt building energy codes in the 1980s. Today, there are several codes. One covers commercial buildings throughout the country (Ministry of Construction 2005). ${ }^{3}$ Three others cover large residential buildings in different climate zones: severe cold/cold, hot summer-cold winter and hot summer-warm winter (see the climate zone map in Figure 1) (Ministry of Construction 2001 and 2003; MOHURD 2009; Lang 2005). The codes cover issues relating to the thermal properties of the building, or building envelope, such as insulation and windows. They also include provisions for efficient heating, ventilation and air conditioning. They do not include provisions on lighting, which are covered in a separate regulation (Shui et al 2009).

\section{Figure 1. Map of China's Climate Zones}

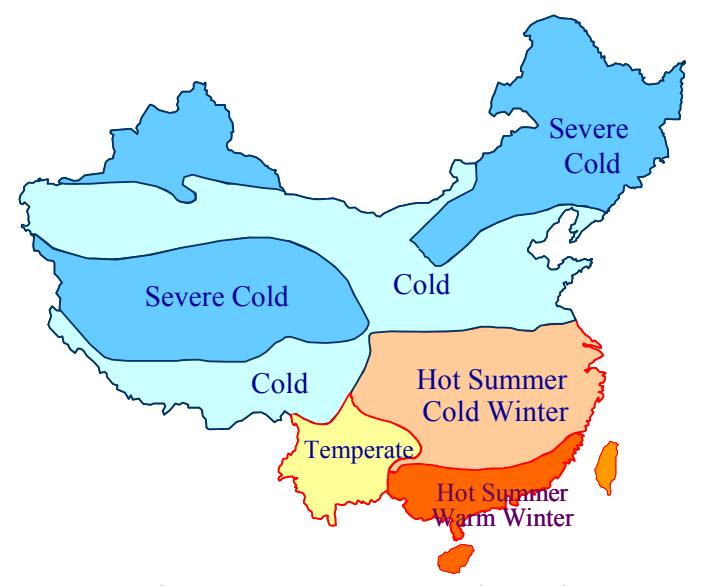

Sources: Lin 2008; Huang and Deringer 2007

The Chinese codes provide two options for compliance: a prescriptive path which provides detailed specifications for individual building components, and a performance path, which requires that the proposed new building not consume more energy (in its design) than a reference building. For the most part, the prescriptive requirements in China are slightly less stringent than those in force in the U.S. today, particularly for warmer regions (Evans et al 2009). (This analysis does not take into consideration the newest versions of the U.S. model codes, which have more stringent requirements than those in force today.) While the Chinese codes are now mandatory at the national level, local governments can adopt more stringent standards. In other words, the Chinese system is somewhat like the U.S. system of model energy codes, with a single national version, but different local adaptations of this national model.

\footnotetext{
${ }^{3}$ The Chinese code uses the term public buildings, which is quite similar to the U.S. concept of commercial buildings.
} 


\section{Methodology}

China has significantly enhanced its building energy code enforcement system in recent years. Because the system has been undergoing change, there is not a large body of literature describing how the current system works. ${ }^{4}$ This article will hopefully contribute to the understanding of China's building energy code implementation. The authors have benefited greatly and learned much from their ongoing collaboration with Chinese experts on building energy code enforcement. In particular, PNNL is collaborating with the Chinese Academy for Building Research (CABR) on enhancing code enforcement in two Chinese cities, Changchun (in the north) and Ningbo (just south of Shanghai in a milder climate zone). ${ }^{5}$ PNNL also previously prepared a comparative analysis on building energy codes in the Asia-Pacific Partnership countries (Shui et al 2009; Evans et al 2009). ${ }^{6}$ Through this collaboration, we have been able to meet with many stakeholders both at the national and the local level, including:

- $\quad$ The Ministry of Housing, and Rural and Urban Development (MOHURD), which adopts the codes and standards and oversees their implementation;

- $\quad$ CABR staff and other technical experts who have participated in the development of the building energy codes;

- $\quad$ Experts from laboratories that test windows and materials for their energy efficiency;

- Local representatives of all the institutions involved in building energy code enforcement (construction administration departments, quality control and testing stations, and third party verifiers and supervisors);

- $\quad$ Developers and construction companies; and

- Manufacturers' associations.

The description below is based on these discussions and Chinese documents such as the codes, training materials and related presentations.

\section{Institutions}

China has multiple institutions involved in building code implementation. At the national level, MOHURD is responsible for adopting and overseeing code implementation. CABR has played the lead role in drafting the codes, and providing training and support for implementation.

At the local level, there are both government institutions and private, third parties involved in building energy code enforcement.

Local oversight of building energy code enforcement is in the hands of a construction administration department ${ }^{7}$ in each jurisdiction. These government departments report to

\footnotetext{
${ }^{4}$ While there is literature in China on the codes themselves, there is very little published information on the implementation and enforcement system. It is also fair to say that few countries have substantial peer reviewed literature on how their code enforcement system operates.

${ }^{5}$ Changchun is in Jilin Province, in the severe cold climate zone. Ningbo is in Zhejiang Province, in the hot summer cold winter climate zone.

${ }^{6}$ The Asia-Pacific Partnership for Clean Development and Climate includes Australia, Canada, China, India, Japan, Korea and the United States. The building energy code reports on APP countries are available at: www.energycodes.gov/implement/country reports.stm.

${ }^{7}$ Construction administration department is also sometimes translated as construction bureau.
} 
MOHURD, but are paid for by the local jurisdiction (the same jurisdiction that adopts the local version of the code). They issue approvals based on the documentation provided by others in the enforcement process.

The quality supervision and testing stations are not government entities but they are funded and authorized by the local government. They work on behalf of the local government. These stations play a role similar to that of most local building code departments in the U.S.: inspecting the building occasionally during construction, and reviewing and approving documents associated with compliance. ${ }^{8}$

These two government-funded entities are somewhat like book-ends around an elaborate system of private, third-party compliance. The core compliance institutions are, in fact, private, third parties. A design verification company must review the design of the building and certify that it complies with the code. And a separate construction supervision company must have staff on-site throughout construction to check whether the building complies with all constructionrelated codes as the building is built. In fact, in most large buildings, there will be a team of onsite supervisors or inspectors continuously present during the construction. These supervisors are somewhat like the managers in construction companies, but they still can greatly enhance compliance because they simultaneously provide a check on the construction companies. In addition, the construction company itself must develop and implement a quality assurance program that helps to ensure compliance. ${ }^{9}$

The third party professionals responsible for verification and supervision must all take training courses and pass elaborate national licensing exams before they are allowed to practice. The licenses are issued directly by MOHURD. When the professionals make mistakes, they can have their licenses temporarily suspended or permanently revoked. Beginning in 2008, third parties can also lose their licenses for violations related to the building energy code, but to date, no one appears to have lost their license over a building energy code issue.

In addition to these organizations involved in checking compliance at the construction stage, there are also many laboratories that evaluate the energy performance (or thermal resistance) of specific building components like insulation and windows. Knowing this performance level is important because it allows all those involved to know whether the specific components match the building plans and hence, ensure that the building under construction complies with the code. A central government authority certifies these laboratories; it is not very difficult to get certification, and there are hundreds of accredited certification laboratories. MOHURD is working to make the system more consistent, though.

\section{Enforcement System}

To build a new building in China, or in most of China, a developer must go through several steps. Before going into the details, however, it might be helpful to provide a brief summary of the key steps (see Figure 2).

For most of this process, the developer begins each step with a request. It must also hire third parties to do the work (designing, building, or checking the design and construction). The quality supervision and testing station reviews the documents completed by the third parties and

\footnotetext{
${ }^{8}$ In the United States, local building departments also issue construction and occupancy permits, while in China, the quality supervision and testing stations provide approval but do not formally issue the permits.

${ }^{9}$ China is a large country and the building code enforcement system has been changing rapidly. In some cities, there are variations on this basic pattern.
} 
conducts some of its own checks. It then gives the developer approval documents. The developer brings these documents to the local construction administration department, which formally issues the paperwork to proceed with each stage of construction, as outlined above. These steps are essentially the same for all aspects of building code compliance, not just energy code compliance. For the most part, all aspects of the building code compliance system are integrated, but there are some special forms and procedures that are unique to the energy code. Understanding the details, however, helps in understanding how rigorous the Chinese system can be.

Figure 2. Key Code Enforcement Steps in Chinese Building Construction

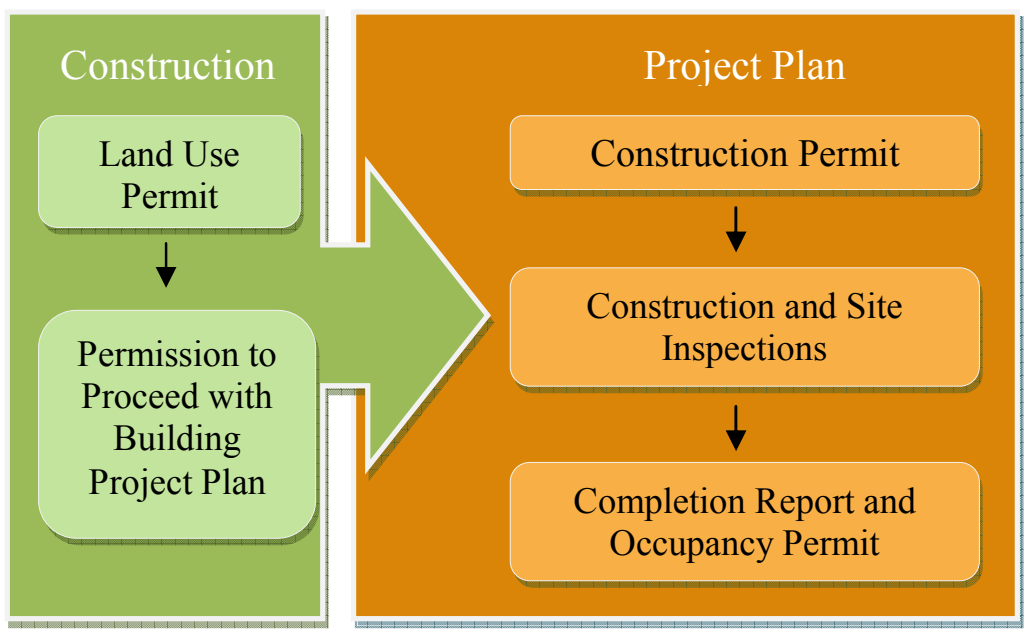

Land Use Permit and Building Design. First, the developer must apply for approval to develop or modify a particular site (a land use permit) from the local construction administration department. Because land in China is owned by the state, the developer must pay for the land use permit, which can be expensive, reflecting the value of the real estate. This approval and payment simply starts the construction and code enforcement process. Next, the developer seeks bids from licensed architects, construction companies, design verification companies and construction supervision companies. The quality supervision and testing station checks the bidding documents to ensure that only certified companies and licensed individuals have participated in and won the award for the respective pieces of work.

The architect or building designer then designs the building, and the winning design verification company checks the building plans for compliance with the building energy code. In most cases, design institutes do the design work. They typically use design software that has an integrated tool for code compliance. In the past, when there were few penalties for noncompliance, they may not have used the compliance tool systematically. Today, in most cities, they would have difficulty getting their plans approved without printing a compliance report. The challenges with compliance at the design stage today relate mainly to rural areas, and in some cases to the way the compliance tool checks more complex designs.

Permission to Proceed with Building Project Plan and Plan Review. The construction administration department must then issue permission to proceed with the building project plan. 


\section{Box 1. Software for Building Energy Code Compliance in China}

Most Chinese building designers use software to ensure that their designs comply with the building energy code. There are several software packages available on the market, all privately developed and available for a fee.

The most commonly used software is called PKPM-Energy, with a market share of between 50 and $70 \%$. PKPM is Chinese software that functions like Auto-CAD, allowing building designers to develop the detailed plans for a building (CABR 2009). There are four options for add-on software to check for compliance with the energy code, one for each of the national building energy codes; for simplicity, we will call these add-ons collectively PKPM-EC (for energy conservation).

PKPM-EC can automatically check the building design for compliance with the energy code. Unlike U.S. energy code software, PKPM-EC is fully integrated into the building design software, which can save a lot of time and, as such, allow architects to better integrate energy features into the building. PKPM-EC first reviews a complete design to determine if it meets the prescriptive requirements of the code. If it does not, it then runs building energy simulation software (based on the U.S. DOE-2 software) to see if the building complies via the performance path. The fact that it integrates building energy simulation software is also an innovation. (While U.S. designers have been using simulation software for years, the main code compliance software, COMcheck ${ }^{\mathrm{TM}}$ and REScheck ${ }^{\mathrm{TM}}$, do not now integrate simulation. Rather this software allow designers to easily consider simple trade-offs to the prescriptive requirements of the code.) However, the simulation in Chinese software can also cause problems because it requires additional expertise to use properly. Many building designers do not have significant expertise in building energy simulation software, so they may mistakes, which in turn can negatively impact the actual compliance of the design.

In addition to the PKPM-EC software, the PKPM-EC developers have also created separate but compatible software for code officials to review the results. Some city officials also have their own spreadsheets to check the results. Other major competitors to PKPM-EC include TianZheng and Si Wei Er (the latter uses a simulation engine designed by Tsinghua University instead of DOE-2). Unlike in the U.S., users must pay for the software.

After the design is complete, the selected design verification company checks the design in detail to ensure that it complies with the building code. It sends a compliance report to the developer and to the quality supervision and testing station, which then forwards approval to the construction administration department. Both the design institute and the design verification company typically use software to check if the building complies with the building energy code (see Box 1). ${ }^{10}$ The design verification company checks the building for compliance with all aspects of the building code, including structural and fire provisions.

Construction Permit. The construction administration department issues a permit to begin construction based on the assurances on the quality supervision and testing station. With this document in hand, the developers can then work with the quality supervision and testing station to develop a detailed construction and compliance plan. After each of the third parties receives their orders, construction can begin.

Construction and Site Inspection. During construction itself, there are several systems to try to ensure compliance with the building energy codes and quality construction. Figure 3 provides an overview of how the process works.

\footnotetext{
${ }^{10}$ For additional information on this software, see also www.pkpm.com.cn/.
} 
The construction company itself must have a quality assurance system in place. The quality control and testing station reviews the construction company's quality control protocols and system design during the permitting process.

The construction supervision company has staff on site throughout the construction process who oversee the work of the construction workers and ensure that the construction matches the original design and complies with the code. This company works on behalf of the developer. PNNL staff visited a construction site in Changchun; for 4 large condominiums under construction, there were 13 staff from the construction supervision company at the site, 8 of whom remained there all day every day. These staff will monitor the construction and order a series of tests to ensure the quality of the construction. The section below on the Acceptance Code describes these tests in more detail. When the construction supervision company finds a flaw in construction, it can and will order changes. These changes can range from completely redoing a portion of the construction to other less severe penalties, depending on the particular problem.

The quality supervision and testing station also conducts both scheduled and random inspections, and at a minimum they will be on site for the pouring of the foundation, completion of the main structure and before finalization of the building. Inspections are typically more frequent when the third party companies are in good standing on their certification. The station can issue stop work orders and require revisions when work is not properly done. For example, we interviewed the head of the Ningbo Quality Supervision and Testing Station, who mentioned that when the new Acceptance Code was first released, they found many problems with code implementation. The most typical problems related to how the exterior insulation was installed and the R-value of the insulation. In many instances, construction companies were required to redo work to bring buildings into compliance. Now, the situation in Ningbo has improved and all the parties have a much better understanding of how to comply. In Ningbo, the quality supervision and testing station has 40-50 staff, of whom 3-5 have detailed energy expertise (for example, they might be heating engineers).

Figure 3. Construction Site Inspection Roles

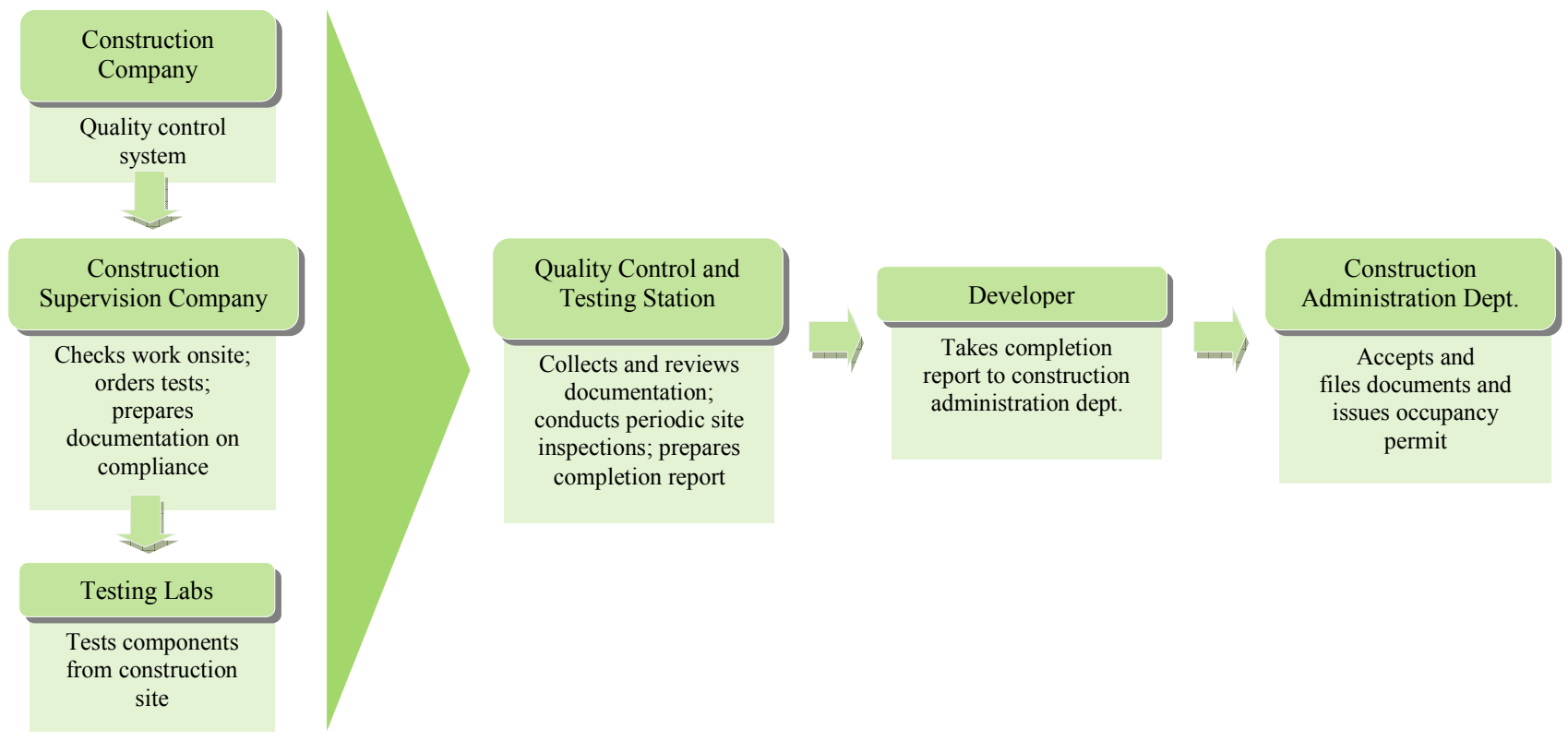


Completion Report and Occupancy Permit. Once construction is complete and all the necessary tests and documentation finished, the quality supervision and testing station prepares a document called a completion report. It signals the station's approval of the documents demonstrating compliance. It gives this and a complete copy of the compliance records to the developer. The developer takes this paperwork to the local construction administration department to apply for an occupancy permit. Once the construction administration department issues that permit, the process is complete and the developer can sell, rent or occupy the building.

For an American audience, this process may sound expensive and time-consuming. In practice, it seems to work relatively smoothly. The Chinese stakeholders did not believe that the system was very costly. Such a system might be more expensive in the United States because of the differences in average wages and because of the smaller scale of most building projects in the United States. However, some aspects of the system, such as construction supervision, may take place but in a different form in the United States. Our Chinese counterparts were instead surprised to hear how few people were involved in compliance checking in most jurisdictions in the United States.

\section{Code for Acceptance and Recent Changes to Enforcement}

The release of the Code for Acceptance of Energy Efficient Building Construction, issued by MOHURD in 2007, is also a critical part of governmental regulatory efforts to implement building energy codes in China (Ministry of Construction and General Administration of Quality Supervision, Inspection and Quarantine of the People's Republic of China 2009) ${ }^{11}$. The Code for Acceptance covers construction quality, testing and documentation for the building envelope (wall, window, door, roof and floor), heating, heating, ventilation and air conditioning (HVAC) systems, lighting, monitoring and controls. It applies to new construction, and additions and retrofits of existing buildings. The Code is almost 70 pages long.

It provides details on issues like how to check if exterior insulation materials have bonded to the wall correctly (see Figure 4), the parts of the HVAC system that need to be inspected and how, and what on site tests need to be done to ensure compliance. For each item in the Code, there is a description of the item, a list of the specifications that item must meet, a brief description of the inspection method and how many items must be inspected (typically from 5 to $100 \%$ of total quantity in a building). Figure 5 provides a summary of the documentation required under the Code for Acceptance.

11 The Ministry of Construction became MOHURD in 2008. The English version of the Code for Acceptance was published in 2009, although the Chinese version first came out in 2007. 
Figure 4. Two Workers Install Insulation in a Typical Chinese Residential Building

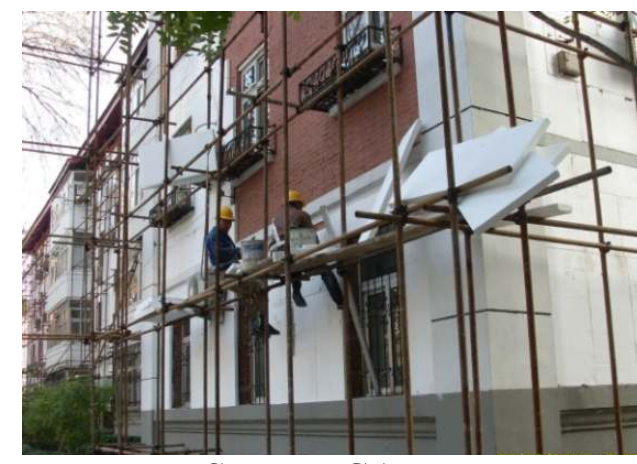

Source: CABR

Figure 5. Summary of Code of Acceptance

\begin{tabular}{|c|c|}
\hline $1-3$ & General Provisions, Terms and Basic Requirements \\
\hline $4-13$ & Energy Efficiency Checks/Specifications of 10 Items (e.g., Roofing) \\
\hline 14 & Site Inspection of Energy Efficiency Work \\
\hline 15 & Quality Acceptance of Divisional Work of Building Energy Efficiency \\
\hline \multicolumn{2}{|c|}{ Appendices A-C } \\
\hline \multicolumn{2}{|r|}{$\begin{array}{l}\text { Appendix A Reinspection Items of Materials \& Equipments on Construction Site of } \\
\text { Building Energy Efficiency Work }\end{array}$} \\
\hline \multicolumn{2}{|r|}{$\begin{array}{l}\text { Appendix B Forms for Quality Acceptance of Building Energy Efficient Divisional, Sub- } \\
\text { divisional Works \& Inspection Lots }\end{array}$} \\
\hline \multicolumn{2}{|r|}{ Appendix C Inspection of Energy Efficiency of External Wall with Core } \\
\hline Expl & ation of Wording in the Code \\
\hline
\end{tabular}

Source: Adapted from Ministry of Construction and General Administration of Quality Supervision, Inspection and Quarantine of the People's Republic of China 2009. this Code:

A few examples of how this works on a practical level might help illustrate the value of

- Several separate items relate to wall insulation. In each building, the construction supervisor must check the documents for $100 \%$ of the insulation materials to ensure that they match the design requirements. However, manufacturers in China often do not provide the results of thermal resistance tests for their products. Thus the code also requires the construction supervisor to test samples of the material (often by sending them to a test lab). For insulation, they must do this for 3-6 samples (depending on the building size) of each insulation product used. They also must conduct spot checks on the building to ensure that the thickness of the insulation and the bonding are as required.

- For HVAC, some of the required items include documentation of test runs and adjustments to ensure that the air volume and temperatures are as estimated. This must be done for $100 \%$ of the installations. 
Thus, effectively, China has requirements regarding not just design and construction but also building commissioning as a result of the Code for Acceptance.

China has numerous testing laboratories, which is clearly essential if the materials are tested from each construction site rather than from each manufacturer. In the United States, manufacturers usually find it to their advantage to have materials tested so that users can more easily understand how they help meet code requirements. In China, there are so many small manufacturers of windows and insulation (in particular expanded polystyrene boards), and they may make custom products for large construction projects. As a result, the system emphasizes having laboratories do sample tests from the construction site. One window test may cost 3,500 yuan (or about \$515). The low cost and the proliferation of test labs without rigorous certification requirements do appear to create weaknesses in the Chinese implementation system. $^{12}$

The Code for Acceptance represents one of several recent changes in the Chinese building energy code system designed to improve compliance. Also in 2007, the government began providing penalties for non-compliance. These penalties range from revoking licenses to fines to requirements to correct non-compliant buildings or building components. An occupancy permit can be held up over non-compliance with energy code issues now. In addition, the government is providing several important types of support for compliance. Buildings that exceed the code are eligible for financial benefits and relaxation of some zoning requirements in many local jurisdictions. The financial benefits are particularly large for incorporating solar energy installations into a building. CABR is also providing training and support to improve implementation of the building energy code. CABR has expanded its training and public relations campaigns associated with each code revision. Local governments also provide an increasing amount of technical support to enhance code awareness and understanding.

\section{Enforcement Monitoring}

In the past, enforcement of the building energy codes was problematic across China. Today, the enforcement levels are much higher in the large cities, where the government decided to concentrate its initial efforts for stronger enforcement. Since 2005, MOHURD has conducted an annual inspection-based survey of building energy efficiency and mitigation in key Chinese cities across the country. For example, the 2008 survey involved travel to 55 large Chinese cities, including provincial capitals, four municipalities (such as Beijing and Shanghai), and five subprovincial cities (such as Ningbo and Qingdao).

MOHURD usually sends nine to ten survey teams in the fourth quarter of each year. The national survey lasts one month or so. MOHURD sends a notice about the survey to the selected cities two weeks before the survey takes place.

A key component of the survey relates to enforcement of building energy codes. The selected cities are required to provide a complete inventory of the building projects submitted since the last survey. The survey team will randomly inspect twelve projects. Of these, it will examine the building design drawings for six projects (including 4 commercial building projects and 2 residential building projects). For the remaining six, the survey team will review the documentation about the construction and, in some cases, visit the completed building. This

${ }^{12}$ For more information on testing laboratories, please see CABR 2009; National Center for Quality Supervision and Testing of Building Engineering 2009; and General Administration of Quality Supervision, Inspection and Quarantine of the People's Republic of China 2008. 
methodology is excellent in that it is applied consistently across the cities sampled. At the same time, the survey may be biased toward larger cities, which typically have better enforcement rates. Also, the lack of continuous sampling that would allow for random checks during construction may mask problems and differences between documentation and actual construction, particularly regarding sealed building components.

Local construction administration departments are scored based on the inspection results, and the scores are sorted from high to low. The work teams will send notices for compliance violations to failed projects. Some provinces, such as Zhejiang, have conducted additional provincial surveys on the enforcement of building energy codes annually since 2005. Zhejiang Province actually conducts several surveys each year to monitor compliance.

\section{Lessons Learned}

\section{For China}

China has made major progress in enforcing building energy codes in its major cities. This is an important achievement, particularly in the short period since the government rolled out its enhanced implementation program in 2007. At the same time, China still has opportunities to improve the efficiency of new buildings and its building energy codes. Below is a brief summary of these opportunities:

- $\quad$ Enforcement in smaller towns and rural areas. For the most part, building energy codes are not enforced in smaller towns and rural areas, which tend to be much poorer than the cities. China is not unique in this pattern of enforcement, but given the extent of new construction in so-called rural areas in China, this is an important area for future work. The reasons for the lower enforcement rates in rural areas are many, but two in particular seem to stand out. The first is the existing capacity and infrastructure for code enforcement in these areas-there is much potential to strengthen it. The relatively rigorous system for enforcement described above does not extend to rural areas. The second is that, in rural areas in particular, many of the buildings under construction are single-family homes. The current codes are not targeted to address energy issues in small buildings, and these buildings traditionally have not had heating or cooling. There is little enforcement of any building codes, even for structural issues, in such homes, which adds to the complexity of the challenge.

- $\quad$ Test ratings. China's existing system of testing building components for their energy characteristics has potential loopholes. Examples of building components that may be tested include windows, insulation and air conditioning units. Manufacturers can apply to multiple test labs and pick the best results. Labs are numerous and could be better regulated. The test protocols are also not as rigorous as they could be. While test ratings may seem like a small detail, inconsistent results can have a large impact on the energy efficiency of a new building. In contrast, in the U.S., there are fewer laboratories and the certification process is quite rigorous. Manufacturers have clear incentives (through the code) to have their products rated, and once the products are rated, the rating applies to the model broadly, not on a project specific basis.

- $\quad$ Consistency of software results. China has made some major technical achievements with its current code compliance software. At the same time, the government recognizes that the software 
sometimes provides inconsistent results. Several factors contribute to the inconsistencies including: the lack of protocols for building simulation in code compliance, lack of protocols to test the software, and user errors compounded by the complexity of the software. Developing rigorous building modeling protocols could help ensure that software used in the compliance process yields consistent results. In the US, there is a long standing protocol for low-rise residential buildings developed by the Residential Energy Services Network (RESNET http://www.resnet.us/) for use in Home Energy Rating Systems (HERS). A new protocol is being developed by the Commercial Energy Services Network (COMNET - http://imt.org/comnet.html) for commercial buildings. Other reasons for inconsistent results may be related to the technical complexity of the software. Simpler user interfaces, test protocols and rigorous testing may be helpful in addressing this issue. In the U.S., the most commonly used compliance software (COMcheck and REScheck) is not as complex, which creates some disadvantages. Yet the simple user interface does help users with compliance and clear algorithms in the code for software calculations help ensure consistent results from all the approved software.

- Easier access to training and more user-friendly information. Most of the information currently available on the building energy code is quite technical. This is not surprising, but at the same time, it may complicate enforcement because most people in the construction industry are not building energy experts. CABR does offer training seminars when each new version of the code is released. Providing easier access to training could help give knowledge of the codes to more people, particularly in smaller towns, (for example, free, downloadable training videos might provide an inexpensive way of expanding access). Likewise, customizing training and materials to different stakeholder groups can be an effective way of reaching those groups. Simple information with pictures can help reach audiences with less expertise in building energy efficiency.

- Increasingly rigorous codes. China has a solid set of building energy codes. The requirements are not significantly weaker than most of their neighbors, yet they could be stronger. Most large countries are undergoing major reviews of their building energy codes in order to significantly strengthen the energy efficiency requirements (which in most cases is still highly cost-effective for building occupants). China may also want to consider such revisions.

\section{For the United States}

During the course of a several trips to China, the authors identified a number of potential "lessons learned" for the United States from their Chinese collaborators. Three lessons standout - the extensive use of third parties in code compliance, the "industrialization" of the construction and code compliance processes, and the use of integrated design and code compliance software.

Perhaps the most significant lesson learned is the extensive use of third parties in the energy code compliance process. These third parties provide plan review, on-site inspection and testing in addition to the plan review and inspections provided by local code officials. ${ }^{13}$ The Chinese have a unique system of blending private entities (hired by the building owner or developer) with government-funded ones for the inspections. Given the challenges many local governments in the U.S. face in staffing, this type of approach might be useful to consider. This type of approach can increase the cost of construction by requiring the building owner/developer to pay for part of the effort to prove that his/her building meets code, but this approach is simply

\footnotetext{
${ }^{13}$ There are several jurisdictions in the U.S. that involve third parties in the enforcement process already, but typically not to the extent that occurs in China.
} 
an extension of the common U.S. approach to requiring owner/developers to pay fees for construction permits. In the Chinese approach, part of those fees goes to hire third party testing and evaluation companies. These companies are licensed and overseen by the local code officials, but paid by the owner/developer.

The use of third party testing and evaluation services tie in nicely with the second lesson learned which is that the Chinese have successfully "industrialized" the building construction and code compliance processes. Given the scale of building construction in China, this is perhaps not surprising. At one typical construction site visited in Changchun, perhaps 20 new high-rise multi-family apartment buildings were in various stages of construction. All of these new buildings, and the surrounding existing buildings, used much the same design and materials. This uniformity of construction lends itself not only to economies of scale in the construction process, but also to the potential to develop a rigorous methodology for testing and evaluation that can be applied to every building. As noted above, China has developed a formal set of testing and acceptance requirements for new construction and this concept has not been applied in the U.S. (Ministry of Construction and General Administration of Quality Supervision, Inspection and Quarantine of the People's Republic of China 2009). Most U.S. construction is "unique", or "one off" and developing formal written and published test plans and methodologies would be very hard given the diversity of U.S. construction. However, this sort of written test methodology idea could be applied in subsets of the U.S. market that do have much in common. It is possible that a published test methodology could be written for homes built by production builders (such as those that work with DOE's Building America program), or for easily identifiable segments of the commercial sector such as "big box" retail buildings or warehouses.

A third significant lesson from China is provided by the use of integrated design and code compliance software. As noted above, China has developed its own computer aided design (CAD) software linked to a DOE-2 energy simulation engine. The advantages of such software are that it allows architects to check for compliance with the energy code as they design a building, not after the core design work is complete. In addition, a built-in simulation engine provides for added flexibility in meeting the code through trade-offs in different elements of the building envelope. There have been a number of attempts to develop such software in the U.S. and there are some linkages of this type, but no single system has achieved great prominence. Examples in the U.S. include the now-withdrawn COMcheckPlus software developed by DOE (DOE 2003), the connection between Google Sketchup and EnergyPlus using Open Studio developed by DOE (DOE 2009), the Energy Gauge Summit Premier software developed by the Florida Solar Energy Center (FSEC 2010), and the Green Building Studio software plug-in available for Autodesk Revit Architecture software (Autodesk 2008). This type of software is a "holy grail" in the energy code world as it allows designers to use their regular design or drafting tool, and get feedback about the energy efficiency of their buildings in the critical design stage of the building. The lesson from China is that this type of software can be developed and used successfully. However, China's experience with this software has not been without problems. Whole building simulations results in China have varied quite a bit, but this may be more of a function of users unfamiliarity with simulation tools or of the assumptions that have to be made to run these tools. 


\section{Conclusions}

Building energy codes are particularly important in China because they help set the energy footprint of new buildings, and China is undergoing a sustained construction boom. However, codes are only useful if they are implemented.

China has made important progress on building energy code implementation in recent years. It has shifted from a system of incomplete compliance to one where compliance appears very strong in the large and medium-sized cities. The system is robust, with multiple levels of checks. It addresses building design, construction and commissioning. The U.S. can potentially learn from and adapt China's achievements in several areas. At the same time, China has opportunities to improve its enforcement system, particularly in rural areas and in making its system more user-friendly. These two points are linked because as enforcement improves outside of the largest cities, it will be increasingly important to ensure that stakeholders from a broad range of backgrounds can understand and implement the code.

\section{References}

Autodesk. 2008. BIM and the Autodesk Green Building Studio. Available at: http://images.autodesk.com/adsk/files/bim_and the autodesk_green_building_studio_20 08.pdf. San Rafael, CA: Autodesk.

China Academy of Building Research (CABR). 2004. PKPM CHEC. Software brochure (in Chinese). Beijing: CABR.

CABR. 2009. Introduction of Certification System of CABR (brochure). Beijing: CABR.

DOE. 2003. COMcheck-Plus Users Guide. Available at: http://www.energycodes.gov/comcheck/pdfs/plus ug_3 03.pdf. Richland, WA: Pacific Northwest National Laboratory.

DOE. 2009. OpenStudio, available at:

http://apps1.eere.energy.gov/buildings/energyplus/openstudio.cfm. Washington, DC: DOE

Evans, M., B. Shui and A. Delgado. 2009. Shaping the Energy Efficiency in New Buildings: A Comparison of Buildings Energy Codes in the Asia-Pacific Region. PNNL-122267. Richland, WA: Pacific Northwest National Laboratory.

Florida Solar Energy Center (FSEC). 2010. EnergyGuage Summit: Commercial Building Energy Analysis Software. Available at: http://energygauge.com/flacom/default.htm. Cocoa, FL: FSEC.

General Administration of Quality Supervision, Inspection and Quarantine of the People's Republic of China; Standardization Administration of the People's Republic of China. 2008. “《建筑外门窗保温性能分级及检测方法 GB/T8484-2008》” (Graduation and 
Test Method for Thermal Insulating Properties of Doors and Windows GB/T8484-2008). Beijing: Standards Press of China.

Huang, J. and J. Deringer. 2007. Energy Efficiency Building Standards in China. Available at: www.asiabusinesscouncil.org/docs/BEE/papers/BEE_Policy_China.pdf. Hong Kong: Asia Business Council.

International Energy Agency (IEA). 2007. Energy Balances of OECD Countries. Paris: IEA.

IEA. 2009. Energy Balances of Non-OECD Countries 1971-2007. Paris: IEA.

Lang, S. 2004. Progress in energy-efficiency standards for residential buildings in China. Energy and Buildings 36, No. 12 (December): 1191-1196.

Lang, S. 2005. Energy Efficiency Requirements for Cooling and Heating Sources in GB501892005 Design Guide for Energy Efficiency in Public Buildings. China Construction Heating \& Refrigeration. No. 7.

Lin, H. 2008. A Brief Introduction to the Chinese Design Standards for Energy Efficiency in Residential Buildings. Working Paper. Beijing: China Academy of Building Research.

Ministry of Construction. 2001. “《夏热冬冷地区居住建筑节能设计标准 JGJ1342001》(Design Standard for Energy Efficiency in Residential Buildings in the Hot Summer and Cold Winter Zone JGJ134-2001)". Beijing: China Architecture and Building Press.

Ministry of Construction. 2003. “《夏热冬暖地区居住建筑节能设计标 JGJ75-2003》(Design Standard for Energy Efficiency in Residential Buildings in the Hot Summer and Warm Winter Zone JGJ75-2003)”. Beijing: China Architecture and Building Press.

Ministry of Construction. 2005. “《公共建筑节能设计标准 GB50189-2005》(Design Standard for Energy Efficiency of Public Buildings GB50189-2005)”. Beijing: China Architecture and Building Press.

Ministry of Construction and General Administration of Quality Supervision, Inspection and Quarantine of the People's Republic of China. 2009. National Standard of the People's Republic of China: Code of Acceptance of Energy Efficient Building Construction. GB 50411-2007. Trans. Li Dan. Beijing: China Planning Press.

MOHURD. 2009. “《严寒和寒冷地区居住建筑节能设计标准 JGJ26-2009》 (Design Standard for Energy Efficiency in Residential Buildings in the Severe Cold and Cold Zones JGJ26-2009)”. Beijing: China Architecture and Building Press. 
National Bureau of Statistics of China. 2008. China Statistical Yearbook. Table 14-37 Floor Space of Buildings Constructed by Construction Enterprises. Available at: www.stats.gov.cn/tjsj/ndsj/2008/indexeh.htm. Beijing: China Statistics Press.

National Center for Quality Supervision and Testing of Building Engineering. 2009. Introduction of the National Center for Quality Supervision and Testing of Building Engineering (brochure). Beijing: National Center for Quality Supervision and Testing of Building Engineering.

Shui, B., M. Evans, H. Lin, W. Jiang, B. Liu, B. Song and S. Somasundaram. 2009. Country Report on Building Energy Codes in China. PNNL-17909. Richland, WA: Pacific Northwest National Laboratory. 